\title{
Characteristics of temporal and spatial evolution of rainfall under the influence of urbanization-A case study of the Beijing-Tianjin-Hebei region
}

\author{
chencgehng $\mathrm{xu}^{1}$, chuiyu lu ${ }^{2}$, and jianhua wang ${ }^{2}$ \\ ${ }^{1}$ Anhui University of Science and Technology \\ ${ }^{2}$ China Institute of Water Resources and Hydropower Research
}

November 26, 2020

\begin{abstract}
Based on the rainfall data from 197 rain gauge stations for the period 1960 to 2019, linear regression, moving average, and SURFER spatial analysis were used to analyze the temporal and spatial characteristics of rainfall in the Beijing-Tianjin-Hebei region, and compare the difference in rainfall between the mountainous areas and plains, during the flood season. The results show that (1) the overall duration of rainfall in each region of Beijing-Tianjin-Hebei exhibit a downward trend, and the overall spatial performance gradually decreases from east to west. (2) The mountainous areas in the Beijing-Tianjin-Hebei region are prone to light and moderate rainfall events; the plains are more prone to rainfall events at levels above moderate rain, especially rainstorms and heavy rain events; the probability of light and moderate rainfall events in the suburbs is close to that of the urban areas, but the probability of rainfall events at levels above heavy rain is less than that of the urban areas; the probability of rainfall events of all levels in the outer suburbs is higher. (3) Increase in rainfall in urban areas compared to the southern suburbs is greater than when compared with the northern suburbs which are at different stages of urbanization, but the effect of urbanization on rainfall is also reflected in the comparison between the urban areas and the northern suburbs. (4) With increasing urbanization, the built environment in the mountainous areas and plains of the Beijing-Tianjin-Hebei region has continued to grow, and the original underlying surface conditions have changed. Because the urbanization process is faster in the urban areas than in the suburbs, the changes to the underlying surface conditions lead to greater increase in rainfall in urban areas during the flood season compared to the suburbs; the urban areas are also more prone to rainfall events at levels above heav
\end{abstract}

\section{Hosted file}

PAPER-chenghengxu.pdf available at https://authorea.com/users/378880/articles/495290characteristics-of-temporal-and-spatial-evolution-of-rainfall-under-the-influence-ofurbanization-a-case-study-of-the-beijing-tianjin-hebei-region

\section{Hosted file}

figure.pdf available at https://authorea.com/users/378880/articles/495290-characteristicsof-temporal-and-spatial-evolution-of-rainfall-under-the-influence-of-urbanization-acase-study-of-the-beijing-tianjin-hebei-region

\section{Hosted file}

table.pdf available at https://authorea.com/users/378880/articles/495290-characteristics-oftemporal-and-spatial-evolution-of-rainfall-under-the-influence-of-urbanization-a-casestudy-of-the-beijing-tianjin-hebei-region 